\title{
Quando diferentes maneiras de cuidar se tornam problema: o ofício descuidado, uma experiência com a metodologia de instrução ao sósia*
}

\author{
Giselle Reis Brandão ${ }^{1}$ \\ Pontifícia Universidade Católica de Minas Gerais (Belo Horizonte, MG)
}

Este artigo resume uma intervenção realizada com os cuidadores de pessoas com deficiências intelectuais em uma organização privada, em Minas Gerais, sob a abordagem da Clínica da Atividade e que, posteriormente, originou a pesquisa para o doutorado da autora em Psicologia do Trabalho. A intervenção aconteceu com seis cuidadores, entre 2010 e 2011, sob os princípios da metodologia histórico-desenvolvimental de Vygotsky, associados ao método de instrução ao sósia. Adotou-se a análise de conteúdo dos diálogos, inspirada em trabalhos de autores da área, orientada pela relação dialética entre a atividade e o ofício. Além das várias evidências de que um enquadre metodológico pôde ser instalado, levando-os a discutir sobre a problemática posta, foram selecionados dois resultados que enfatizam o potencial metodológico da instrução ao sósia: o desenvolvimento da atividade de um cuidador, ilustrado por um trecho extraído dos diálogos, e os argumentos que indicam a ausência (disfunção) da função psicológica do coletivo de trabalho (o gênero profissional) para aqueles profissionais.

Palavras-chave: Atividade, Cuidadores, Ofício, Intervenção.

When different ways of caring become a problem: the careless profession, an experience with the methodology of instruction to the double

This article summarizes an intervention conducted with caregivers of people with intellectual disabilities in a private organization in Minas Gerais, Brazil, with the approach of the Activity Clinic and which subsequently led to a research for a doctorate by the author in Occupational Psychology. The intervention took place with six caregivers, between 2010 and 2011, under the principles of Vygotski's historical and developmental methodology, associated to the method of instruction to the double. The content analysis of the dialogue was adopted, inspired by works of authors in the area and guided by the dialectical relation between activity and profession. In addition to the many evidences that a methodological framework could be installed, leading the caregivers to discuss the raised issues, two main results were selected to emphasize the methodological potential of the instruction to the double: the development of the activity of a caregiver, illustrated by an excerpt of the dialogues, and the arguments that indicate the absence (dysfunction) of the psychological function of the work collective (the professional genre) for those professionals.

Keywords: Activity, Caregivers, Profession, Intervention.

\section{Introdução}

E ste artigo tem o propósito de compartilhar parte de uma experiência de iniciação teórica e metodológica em Clínica da Atividade (CA), vivida com os cuidadores de pessoas com deficiências intelectuais em uma organização privada em Minas Gerais, realizada entre 2010 e 2012 e que resultou, posteriormente, em uma pesquisa para o doutorado da autora em Psicologia do Trabalho. Como intervenção, o objetivo foi criar condições metodológicas que favorecessem o desenvolvimento da atividade destes profissionais. Como pesquisa, os principais objetivos foram vivenciar a abordagem metodológica proposta, identificando seu potencial e seus limites como recurso de intervenção em Psicologia do Trabalho, e compreender a atividade a partir dos

* Trabalho de pesquisa, com estágio doutoral na França/CNAM, financiado pela Coordenação de Aperfeiçoamento de Pessoal de Nível Superior CAPES, no ano de 2011. Estudo avaliado e autorizado pelo Comitê de Ética em Pesquisa COEP, da UFMG.

1 Doutora em Psicologia do Trabalho pela Universidade Federal de Minas Gerais (UFMG). Professora da Pontifícia Universidade Católica de Minas Gerais (PUC Minas) e coordenadora do curso de especialização em Psicologia Organizacional e do Trabalho pelo Instituto de Educação Contiuada (IEC) - PUC Minas. 
diálogos produzidos. Alguns elementos contextuais são necessários. A escolha pela organização se deu como uma perspectiva de retomar o trabalho com os cuidadores iniciado em 2005sob outra perspectiva teórica e metodológica sob demanda institucional relacionada à melhoria da qualidade do trabalho e das relações entre os profissionais. Já o segundo momento do trabalho (entre 2010 e 2012) não foi orientado por uma demanda institucional, porém logo nos primeiros encontros os cuidadores delinearam a seguinte problemática a trabalhar: como lidar com as diferentes maneiras de agir (de cuidar) do colega direcionadas ao interno e, principalmente, quando se discorda desses modos de fazer. Demanda que já aludia à qualidade do cuidar ali realizado, sendo trabalhada por eles em coanálise, revelando especificidades da atividade naquele contexto. Uma delas refere-se à inexistência de um coletivo de trabalho que funcionasse como um recurso técnico e psicológico para os profissionais, impossibilitando-lhes recriar e reorganizar as regras, os riscos e as condições de realização da atividade. Desprovidos deste recurso, os profissionais recorrem a estratégias de ação individualizantes e solitárias, favorecendo os apelos frequentes e ineficazes à hierarquia e aos comportamentos de favoritismos e delação, deslocando os conflitos da atividade para a ordem de conflitos interpessoais. Entretanto, inexistência de um coletivo de trabalho não impediu que o desenvolvimento da atividade fosse realizado por um cuidador, revelando o potencial metodológico dessa clínica e os desafios que ela nos coloca ${ }^{2}$. Este artigo traz essas duas perspectivas de evidências empíricas.

\section{Principais fundamentos da noção de atividade}

Além das contribuições de Vygotski e Bakhtin, a CA pode ser definida como uma "clínica do trabalho situada na intercessão da ergonomia francófona e da psicopatologia do trabalho" (Lhuilier, 2007, p. 52). Isso porque dois importantes ergonomistas franceses a inspiraram: Wisner (1995) e o exercício da controvérsia, como um recurso de análise sobre as diferentes maneiras de se fazer o trabalho, interessado no seu caráter desenvolvimental; e Leplat (1997), com a ideia de que, ao realizar a tarefa, o sujeito não só se submete, mas cria um meio para viver, transformando algo para si e no contexto, noção que se aproxima daquela de saúde de Canguilhem $(2005$; 2009) e compartilhada por Clot (2010). Na psicopatologia do trabalho, dois psiquiatras ajudaram a sedimentar as bases para uma teoria e uma prática clínicas sobre a atividade: Daumézon (1948), com sua proposta de uma clínica das atividades diante das situações de trabalho terapêuticas no lugar de uma clínica tradicional dos sinais de alienação, e Le Guillant (1985; 2006), que "estabeleceu as bases para uma clínica dos distúrbios mentais produzidos na relação do sujeito com sua atividade" (Lima, 2011, p. 233), tendo como pressuposto a articulação da subjetividade e da doença mental com as relações sociais, entendidas como fonte de conflitos. Outro psiquiatra espanhol importante foi Tosquelles (2009), cuja concepção de atividade estava epistemologicamente próxima daquelas desenvolvidas por Léontiev (1976), Vygotski (1925/2003) e Bahktin (1997) embora não se conhecessem. . Ele rompe com a ideia de atividade como movimento, trabalho muscular, adaptação social ou fazer pelo fazer e a define como "atividade própria: atividade que parte e se enraíza no sujeito ativo para se desabrochar se for o caso, num contexto social” (Tosquelles, 2009, p. 47). Posta no centro de sua ergoterapia, a atividade era um recurso para cuidar do hospital, que significava "mantêlo em estado de acolher a iniciativa do doente e, melhor ainda, de fazer dessa iniciativa uma instituição susceptível de apoiar os processos de humanização" (Clot, 2011, p. 20). No centro está a atividade dos doentes e dos cuidadores, como um cuidado singular que faz do hospital o objeto da atividade destes e não o contrário, revelando uma inversão clínica inexistente: a atividade

2 Por motivos de espaço, não foram incluídas as citações traduzidas dos textos em francês. 
torna-se um instrumento clínico preciso e central, e não o objeto de interpretação para o qual incide o saber e suas classificações. O psicólogo russo Léontiev (1976) também contribui com sua ideia de atividade, associada à consciência e acessada pelo sujeito através das relações com os outros, introduzindo, em seu interior, tanto a subjetividade quanto o coletivo.

Associados a esses nomes, a Psicologia histórica, dialética e cultural de Vygotski foi estrutural para renovar a noção de atividade. Seu objeto é o desenvolvimento da atividade psicológica que compreende articulações entre o psíquico e o fisiológico, que, para ele, configuram o psicológico. O desenvolvimento psicológico, cuja origem é externa, social, funciona simultaneamente como fonte e recurso que se interpenetram para e na ação do sujeito no meio. Através de mecanismos específicos internos à criança (internalização, assimilação, transformação, compensação), associados aos instrumentos psicológicos, ele perpetua-se como estruturação psíquica humana integrando, recriando dinamicamente os processos fisiológicos, as emoções, os conceitos, a linguagem, a consciência e o inconsciente. Para ele, "o individual no homem não é o contrário do social, mas sua forma superior" (Vygotski, 2004, p. 236). Ou seja, qualquer função psicológica superior foi, antes de tornar-se função no indivíduo, uma relação com o outro, uma relação social. O psíquico é a síntese da história da evolução do homem e da história do indivíduo, na qual a linguagem é uma atividade instrumento que move essa engrenagem sociopsíquica. Outras ideias do autor aparecerão no decorrer do texto, auxiliando na compreensão dessa clínica.

Resumindo o conceito de atividade a partir das contribuições mencionadas, tem-se o seguinte: a) a atividade não é mais vista como ação externa, operacional, invariante e adaptativa tampouco desprovida de história e de sentido, que a tornou estranha e oposta à subjetividade, ela ganha o estatuto de um operador clínico a partir de outra concepção de funcionamento psíquico e de subjetividade, segundo a qual a singularidade se faz na confluência do sujeito, com sua ação, seus instrumentos (psicológicos e técnicos) e o coletivo; b) ao mesmo tempo em que expressa uma ação objetiva, ela implica em uma ação subjetiva cujo caráter social e concreto a distingue da intencionalidade e das representações mentais - o desenvolvimento psicológico articula o externo e o interno, o objetivo e o subjetivo; c) a atividade apresenta-se como uma ação, cujo sentido passa também pelo outro e pelas mediações da vida concreta, em que o sujeito não apenas se submete, mas, simultaneamente, intervém no meio, transformando-o e se transformando. A subjetividade se constrói pelo indivíduo, a partir da transformação da atividade social e, por isso, trata-se de uma clínica da atividade e não, a priori, da subjetividade (Clot, 2011). Para instaurá-la, é preciso colocar a atividade em movimento.

\section{Da atividade (psicológica) ao gênero profissional: os caminhos do ofício}

Vimos a partir de Vygotski (1925/2003) que a atividade do indivíduo no meio tem como substrato psíquico a atividade psicológica, a base de toda e qualquer atividade humana no intercâmbio social. Assim, ao agir, o sujeito transforma algo em objeto social e psicológico, simultaneamente. Em objeto social porque ao agir sobre o objeto, o indivíduo age também sobre os outros que possuem relação com esse objeto, e essa relação é constitutiva da atividade do sujeito, também habitado pelas atividades do outro. Portanto, o sujeito não age sozinho, e a realização da tarefa pressupõe acionar uma memória social sobre aquele trabalho (gênero profissional) de início, pela assimilação desse gênero, e, em seguida, este é transformado em instrumento a serviço da ação, um instrumento objeto psicológico. A apropriação psicológica da atividade (do objeto) não se reduz à interiorização das suas características e funções, mas implica sempre sua transformação: de artefato em instrumento e em ato psicológico, por meio dos mecanismos já mencionados. A ação psicológica é esse movimento do sujeito de se desprender, de se ligar e desligar daquilo 
que as atividades sociais que ele estabelece com os outros representam para ele e para os outros (Clot, 2006; 2010). Essa passagem de mudança de função, de um objeto (artefato) que antes foi apropriado pelo sujeito no curso da ação e, em seguida, torna-se meio (instrumento psicológico) para desembaraçar-se da atividade em questão, junto dos outros, Vygotski (1925/2003, 1994) nomeou como migração funcional, sendo essa a base do funcionamento psicológico. Eis aí a função psicológica do (coletivo de) trabalho: "aquilo que se faz no universo dos outros para dele participar ou se separar. É o trabalho assumido pelo sujeito no âmbito do trabalho dos outros" (Clot, 2006, p. 65). Ou seja, o trabalho cumpre, simultaneamente, uma função social e psicológica para o indivíduo e para o coletivo. Existe algo substancial na própria experiência dos trabalhadores que não é explícito, embora presente de diferentes maneiras de dizer, fazer sentir daquele meio profissional, relativo a uma continuidade histórica dessa experiência e que orienta e guia a ação diante dos seus conflitos. Tal memória social se presentifica no âmbito da tarefa, da atividade dos outros, da hierarquia e das várias formas de organização do trabalho.

Tal função psicológica está na base do conceito de gênero profissional desenvolvido pela CA, cuja origem está nos trabalhos de Oddone, Re \& Briante (1981) e de Bakhtin (1997). Transmitir a experiência aos colegas seria uma forma de conhecê-la, reconhecê-la e assim, transformá-la. Essa é a função do método de instrução ao sósia (IS), já desenvolvido por Oddone et al. (1981): explicitar o diálogo interior do sujeito com os elementos que compõem a atividade - consigo, com os outros e com o objeto -, pois ela é triplamente dirigida (Clot, 1998): ao sujeito que se apropria dela e sem o qual ela não existe, ao objeto sobre o qual incide a tarefa, e que carrega suas propriedades e todo o patrimônio social que essa representa; e à atividade dos outros que incide sobre o mesmo objeto, incluindo aí a mediação pelo gênero profissional. Ela representa uma colisão de vários interesses sobre o mesmo objeto que atravessa a atividade de vários outros e que o disputam. Por isso, a atividade é conflito (Clot, 1998). Realizá-la significa considerar todos esses pressupostos e não somente as preferências e preocupações pessoais, afinal é por intermédio da atividade dos outros que o sujeito pode se apropriar do objeto de sua atividade e fazê-la sua. É desse paradoxo que ele extrai sua mobilização psicológica, fonte de toda ação e de toda construção subjetiva (Clot, 1998).

Por meio da atividade realizada, busca-se reconhecer e dar luz ao real da atividade (Clot, 1998) que dela faz parte como uma dimensão do não realizado: tudo aquilo que foi deixado de lado, adiado ou que foi impossibilitado de fazer; o que poderia ter sido feito; o que deveria ter sido feito; o que não pôde ser feito; o que se gostaria de fazer. Essa dimensão do real da atividade não deixou de existir psicologicamente para o sujeito em sua relação com a atividade e ela tenciona a vida psíquica que está em franca conexão com a vida prática. Ganha sentido a afirmação de Vygotski (1925/2003, p. 76): "O comportamento tal como ele é realizado é uma ínfima parte disso que é possível. O homem é pleno a cada minuto de possibilidades não realizadas". A atividade realizada é o que foi possível fazer (libertar-se) diante os impedimentos que podem vir do outro, do objeto ou do próprio sujeito, não sem trair alguma dessas origens, ao mesmo tempo que se vale de outras como recurso.

Este conflito presente no interior de toda atividade e normalmente negado pela organização formal do trabalho assume o estatuto de um problema clínico, e não somente de ordem organizacional, institucional, política ou individual. Quer-se identificar e desenvolver o coletivo de trabalho no sujeito e não seu contrário, afinal cada indivíduo traz em si o social que o constitui, ao mesmo tempo que, agindo no meio, este social é transformado.

A partir da ideia de gênero profissional, Clot (2010) interessa-se pela busca de um trabalho de elaboração coletiva dos coletivos de trabalho, chegando ao conceito de ofício. Este é o resultado deste trabalho de elaboração, amparado na história social e individual desse coletivo, estando as duas em intercessão. Ele funciona como uma exigência que se impõe e também como um organizador da atividade, orientando o sujeito e servindo-lhe de recurso perante o real da atividade, 
aumentando seu poder de ação sobre o meio. Essa conotação psicológica do ofício diferencia-se de outras noções comuns a ele associadas, como a de um elemento exógeno e preexistente à atividade de trabalho, como visto pela Psicologia clássica e organizacional, ou como um coletivo de pertencimento propiciando uma experiência identitária, como em Osty (2003).

Do ponto de vista psicológico, o ofício precisa do indivíduo para existir, mas ele o ultrapassa, o supera, combinando simultaneamente as várias dimensões que o constituem: a impessoal, representada pela organização formal do trabalho, fundada na prescrição da tarefa; a interpessoal, dada pelas trocas entre os profissionais; a pessoal, relativa à maneira pela qual cada um se apropria da atividade, chegando à estilização desta; a transpessoal ou do gênero profissional, representada pela memória social e profissional daquele meio, integrando o passado, o presente e o futuro e funcionando como um meio à disposição de cada um e de todos, simultaneamente. Essas quatro instâncias estão em conflito de interesses na interface com a atividade profissional, sendo tais discordâncias que mantêm o ofício vivo, em desenvolvimento, como ocorre na atividade. Há, portanto, uma dialética relação entre a atividade e o ofício (Litim, 2006), sendo este um instrumento técnico e psicológico para o desenvolvimento desta.

Assim, a CA nos acena com uma base teórica e metodológica que revigora a ideia de trabalho: uma ação do funcionamento psíquico do indivíduo sobre o objeto, que é atravessado pela atividade do outro, explicando a concepção de um coletivo de trabalho como instância psicológica (e técnica), presente em cada membro deste coletivo, como na sua história e também na história daquele meio profissional.

\section{O contexto da intervenção: a organização do cuidado}

A intervenção se deu em uma organização privada, fundada em 1964, voltada ao cuidado das necessidades da pessoa com deficiência intelectual e da sua família, com atendimentos clínicos, cuidados básicos, orientação educacional especial e espaço de convivência.

Seus usuários são jovens, adultos (maioria) e idosos (minoria) com deficiências intelectuais, síndrome de Down, autismo, disfunções neuromotoras, deficiências visuais e/ou auditivas etc. Funciona como entidade educacional e de saúde, dispondo de profissionais como médicos, fisioterapeutas, psicólogos, enfermeiros, educador físico e nutricionista e oferecendo modalidades de serviços de atendimento diário, permanente e periódico. Há também uma assistente social que atua com as famílias, uma profissional de recursos humanos e outros profissionais administrativos, além dos serviços de copa, cozinha, limpeza, lavanderia e jardinagem. O trabalho é organizado em grupos de convivência de usuários/internos, conforme as possibilidades de agrupamento das deficiências e necessidades destes. As atividades cotidianas (de cuidado, de oficinas, de esportes, de alimentação e de higiene) são feitas conjuntamente e acompanhadas por grupos de cuidadores, variando o número destes para cada grupo de internos; geralmente são de dois a quatro cuidadores por grupo, que, em média, possui de seis a dez internos. Há também a modalidade do cuidador particular ou de referência: o profissional cuida de um único usuário/interno, sendo responsável formal por este perante a família e a organização. $\mathrm{O}$ regime de plantão é de $12 \times 36$, tendo uma supervisora por plantão com formação técnica em enfermagem.

\section{Síntese dos fundamentos metodológicos e das ações realizadas}

Orientada pelo princípio da intervenção, a CA concebe diferentemente a intervenção e a pesquisa: por possuírem objetos, destinatários, recursos, objetivos e enquadramentos bem 
distintos, elas não devem ser misturadas. $\mathrm{O}$ risco incide no resultado do que se busca: ajudar os trabalhadores a desenvolver sua atividade ou produzir compreensão e conhecimento pelos e para os pesquisadores? Intervenção e pesquisa podem e devem ser associadas, preservando-se os objetos, recursos e objetivos de cada uma, em momentos distintos (Clot, 2008; Kostulski, 2011). O fundamento disso está na relação entre o saber e o pensamento, os quais assumem estatutos distintos em Vygotski (1934/1997). O pensamento é a ação em movimento, uma atividade linguageira endereçada a si próprio. Pensar não se opõe à ação, mas faz desencadeá-la. Ele é da ordem da surpresa, do imprevisto, da descoberta. Já o saber é uma racionalização que pode impedir o sujeito de pensar, não sendo fonte do pensamento, mas um recurso para pensar/agir. Por isso, colocar o saber como fonte da atividade dialógica (Bakhtin, 1997) a ser provocada na intervenção pode ser um risco fatal, inviabilizando a instauração das condições para que os profissionais desenvolvam seu próprio fazer.

Para desenvolver a atividade, é preciso colocá-la em movimento por meio das trocas dialógicas, com base na metodologia histórico-desenvolvimental de Vygotski, articulada a métodos indiretos de ação (autoconfrontação simples e cruzada; método da IS e outros). Alguns princípios metodológicos também são associados a isso: o da confrontação sobre as diferentes maneiras de fazer (consigo mesmo e entre os pares), o da controvérsia (Wisner, 1995), o da coanálise (Clot, 2006; 2010; Scheller, 2001b) e o do grupo homogêneo (Oddone et al. 1981).

A intervenção teve como objetivo ajudar aos cuidadores a promover o desenvolvimento da atividade com base na demanda posta por eles. Ela realizou-se entre 2010 e 2011 com 6 cuidadores dos plantões I e II ( 3 cuidadores em cada), os quais cuidam de 8 adultos do sexo masculino com sérios comprometimentos motores, psicológicos, neurológicos e fisiológicos. Apenas um cuidador era do sexo masculino e tinha 8 anos na casa; as demais tinham 24 anos, 12 anos, 5 anos, 8 meses e 4 meses de casa. Apenas uma delas possuía curso técnico em enfermagem.

Já o trabalho de pesquisa subsequente à intervenção buscou identificar nos diálogos pontos indicativos de desenvolvimentos possíveis da atividade, bem como entender elementos de interesse científico sobre essa realidade. Esse trabalho ocorreu em 2012 e trouxe maior clareza aos dados empíricos e à abordagem metodológica realizada, considerando-se que a apreensão dessa nova clínica que se propõe desenvolvimental exige um tempo não considerado pelas instituições científicas e seus critérios.

Estes dois grupos foram acompanhados durante quatro meses, em 2010, por meio da atividade de observação com presença semanal e duração média diária de 4 a 5 horas. Nosso objetivo naquele momento era interagir com os grupos e com a atividade, acompanhá-los na ação, realizá-la com eles e fazer-lhes perguntas sobre a atividade, como meio de colocá-la em discussão. Nesta clínica, a observação fundamenta-se em Wallon (1949/2002): o sujeito sob efeito da observação do outro passa a se observar também, e isso altera a maneira como realiza sua atividade, que se torna objeto de diálogo, além de servir como meio de localizar questões específicas e alimentar discussões entre profissionais a partir de traços localizados previamente com eles, sendo ponto de partida para a análise da atividade. Durante a observação tínhamos uma compreensão parcial de seu propósito mais amplo, por isso não trabalhamos com a localização de questões específicas levadas para as análises posteriores.

Utilizou-se o método de instrução ao sósia (IS) (Oddone et al., 1981; Clot, 1998) nos encontros com cada plantão, configurando diferentes momentos: a instrução feita pelo profissional ao sósia (a pessoa responsável pela intervenção), seguida de discussão com colegas, que a escutaram (momento I); a escuta individual da própria instrução e registro, por escrito, de questões de seu interesse (momento II); um momento coletivo para comentários sobre os apontamentos de cada um, na audição da instrução para uma coanálise que se estenderá para outras instâncias, no futuro (momento III). Os momentos I e II ocorrem em dias espaçados e, após finalizarem-se todas as instruções e audições individuais, ocorre o momento III. 
O método indireto de instrução ao sósia é uma espécie de "eu duplicado", pois prevê que o trabalhador instrua o sósia acerca de sua atividade para que ele possa substituí-lo no trabalho no dia seguinte. Tais instruções acontecem com os colegas que realizam a mesma atividade, em dias diferentes, possibilitando-lhes, individual e coletivamente, a organização, a formalização, a validação e a transmissão da experiência deles. Busca-se replicar a experiência vivida: o que antes era uma experiência vivida passa a ser o objeto de uma nova experiência (por meio da intervenção). Nesse movimento, quer-se localizar quais ações psicológicas determinaram a passagem de uma atividade à outra e, por consequência, seu desenvolvimento possível e impossível, possibilitando aos sujeitos, individual e coletivamente, renovar, em sentido e na ação, sua atividade profissional. Então, o desenvolvimento, que é o objeto da intervenção, é, ao mesmo tempo, o meio e o recurso para acessar a atividade, pois "é só em movimento que um corpo mostra o que ele é" (Vygotski, 1978, p. 64). Assim, o método de instrução ao sósia possibilita aos sujeitos: a) recuperar esse caráter duplo da consciência: a ação vivida no passado e a ação vivida no presente, realizando uma nova ação para viver a experiência de um outro jeito; b) reconhecer essa dissonância entre a atividade realizada e o real da atividade; c) elaborar melhor sua atividade, por meio do diálogo (consigo mesmo, com os outros e com o objeto de sua ação). Assim, esse método é um instrumento de elaboração da experiência profissional e um instrumento de formação (Clot, 2006). A atividade dialógica é um meio para que os desenvolvimentos possam acontecer.

Os cuidadores apresentaram os seguintes problemas a ser trabalhados: "Como lidar com os colegas em situação de discordâncias quanto aos modos de agir? Como arbitrar sobre o conflito implícito nas diferentes maneiras de agir do colega, para então agir?". Delineava-se uma problemática rica para a possibilidade de uma intervenção e que dizia sobre a qualidade do trabalho realizado, questão fundamental para esta clínica. Era a sinalização de que podíamos ir adiante. A partir daí, vários elementos da atividade de cuidar puderam ser discutidos, como sua especificidade, que se constitui necessariamente a partir e na relação com o outro, receptor do cuidado, intensificando tais diferenças na ação, as fragilidades organizacionais em lidar com essa dimensão intrínseca à atividade e suas contradições presentes nas regras e nas omissões quanto ao que seja o cuidado ali, os efeitos disso nos cuidadores, que apropriam-se dessas contradições a seu favor, endossando uma perspectiva de ação, de risco assumido e de destino às regras formais, quando levar as questões para a hierarquia e se haveria outras opções, se o cuidado se define pelas condições do feminino e da maternidade, como agir diante do descuidado do colega e os estilos próprios de cada um e por que é permitido a uns descumprirem as regras e a outros não.

Em CA, os caminhos metodológicos de análise dos diálogos são diversos e tendem a uma análise linguística como perspectiva central, associada ou não a outras manifestações da atividade, como a do corpo, a do gesto, a dos afetos (Clot, 2003; Clot \& Fernandez, 2005; Kostulski, 2011; Simonet, 2009; 2011; Tomàs, 2005; Vygotski, 1994; 1925/2003; 1998). As bases dessas análises ainda constituem um caminho incipiente dentro da própria equipe francesa que as desenvolve.

Como não foi possível levar a cabo uma análise linguística propriamente, nos prazos de um doutorado, trabalhou-se a riqueza empírica dos diálogos sob o viés de seu conteúdos como nos trabalhos de Clot (2001; 2010), Caroly e Clot (2004), Litim (2006), Miossec e Clot (2011) e Scheller (2001a; 2001b; 2003; 2007).

A análise teve como eixo principal a dialética atividade-ofício (Clot, 2010; Litim, 2006), identificando características da atividade em sua relação com as quatro instâncias do ofício. Ao tratarem de questões como as mencionadas acima, por exemplo, como se impor diante os colegas, já que as diferenças fazem parte do trabalho, os cuidadores discutiam o ofício de cuidar. Cada um, ao desenvolver e compartilhar seu argumento, colocava em relação as instâncias do ofício: o exercício pessoal da atividade (pessoal), as regras prescritas (impessoal), as regras construídas entre eles (transpessoal) e a atividade com os pares (interpessoal) (Clot, 2010; Miossec \& Clot, 2011). 
Neste caminho, a instância transpessoal ganhou destaque pela fragilidade de sua condição naquela situação. Estes profissionais encontravam-se desprovidos do gênero profissional, pois o trabalho coletivo não conseguia produzir um trabalho de reorganização, de recriação da organização oficial do trabalho. Chegamos neste caminho guiados pela seguinte pergunta: "O que as produções dialógicas evidenciam sobre as relações que os cuidadores estabelecem entre si enquanto um coletivo de trabalho?". A orientação da dialética atividade-ofício trouxe-nos descobertas sobre realizações da intervenção, organizadas em três objetos de análise: a) a instauração ou não da metodologia e do método de IS e suas questões para o pesquisador; b) particularidades da relação da atividade com suas respectivas instâncias de realização; c) a fragilidade da instância transpessoal naquele contexto, levando-nos a supor a ausência do gênero profissional como uma função psicológica atuante para o coletivo.

\section{Algumas evidências empíricas reveladas pela pesquisa:}

A intervenção é um tempo de ação e simultaneamente um tempo de produção de material para a pesquisa. A pesquisa propriamente se faz sobre os traços da intervenção. (Miossec \& Clot, 2011, p. 351)

Neste texto, selecionamos dois resultados para reafirmar o potencial metodológico da IS: o desenvolvimento da atividade de um cuidador, ilustrado por um trecho extraído dos diálogos, e os argumentos para a leitura acerca da ausência do gênero profissional para aqueles profissionais. Infelizmente não podemos transcrever os diálogos em sua extensão, como pede a análise em CA.

Várias são as evidências de que um enquadre metodológico pôde ser instalado e que um trabalho coletivo fora iniciado, permitindo-lhes reviver experiências e, por meio delas, viver outras novas: eles atualizavam e discutiam pormenores do trabalho, falavam do processo na nossa ausência, compartilhavam com colegas as autoconfrontações iniciadas, deixando-se afetar pelo movimento dialógico encadeado pelo método. Uma dessas vivências extrapolou o roteiro metodológico: uma longa mensagem do cuidador Moisés, enviada a nós, por Skype, na qual ele compartilha a emoção vivida após a escuta do CD. Selecionamos parte dela: "Acabei de ouvir meu sósia, estou emocionadíssimo... Nunca pensei que eu fosse tão capaz... Muito obrigado por este documento. Carregarei essa passagem da minha vida para sempre... Meu sonho sempre foi ser reconhecido." No decorrer do processo, ele pôde trabalhar sobre o reconhecimento, como o fez em seu manuscrito, preparado para o momento III da IS (comentários), transcrito em itálico abaixo. Ele inicia seu comentário lendo-o:

83 Moisés: "Meu trabalho é continuação do trabalho do outro. As diferenças e divergências de cada cuidador fazem a missão fluir, pois eu vejo com uma dimensão, e o outro colega vê com outra. Isso faz que várias cabeças pensem mais, chegando a uma só conclusão para atender ao outro com a maior precisão possível. Eu sempre desempenhei meu papel pensando na pele do outro, minhas decisões são tomadas depois de experimentadas em mim, mentalmente. Sei que meu trabalho é cansativo, perigoso, emocionante, mas alguém tinha que fazêlo, então estou aqui, muito feliz por ter uma profissão que nos dias de hoje está no auge e isso me envaidece, me traz fama, além do dinheiro. Saber que sou útil nessa função me traz imensa alegria. Meu emprego [é o] projeto da minha vida. Aí eu repito aqui: a instrução ao sósia me fez pensar mais ainda sobre meu papel, me fez ser mais prudente, mais cauteloso. Sei que, nessa profissão, tem que ser de tudo um pouco, tem que... Eu tenho que ser mãe, eu tenho que ser pai, eu tenho que ser mulher, menino, menina, eu tenho que ser moço, eu tenho que ser rapaz, eu tenho que ser avô, eu tenho que ser avó, eu tenho que ser irmão, padrinho, amigo, colega, cunhada, sogro, sogra, eu tenho que ser crente, eu tenho que ser católico [Carla ri], às vezes, eu tenho 
que ser surdo, às vezes, eu tenho que ser mudo, só não sou Deus porque o próprio Deus mora dentro de mim." Entendeu? E é isso aí que eu tirei da Instrução ao Sósia. [Silêncio].

84 Moisés: Quando eu falo que eu tenho que ser moça, eu tenho que ser mulher, rapaz, eu tenho que ser mulher, porque cada menino tem uma diferença, não é, Ana?

85 Ana: Cada menino.

86 Moisés: Às vezes, a minha posição de homem ali, naquela hora, ele não vai obedecer, aí ele vai obedecer igual a Rosalva te obedeceu. Você fez um papel... Nem de mãe, foi um papel de avó [Carla ri], então, na hora ela estava precisando ouvir era aquilo, e aquilo era o que convenceu ela...

104 Moisés: Quando eu comecei a trabalhar aqui, e o "cdzinho" fez eu entender isso, porque eu não conseguia entender as diferenças dos colegas. Eu achava que todo mundo tinha que agir com emoção [entonação forte], que todo mundo tinha que ser aquela coisa, tem que ser mágico, não sei o quê... Mais aí eu vi que cada [entonação forte] pessoa tem uma personalidade e que aqui na escola se precisa exatamente disso, de todas essas pessoas, precisa de uma de uma pessoa lerdinha para domar aquele menino, precisa de uma valentona para carregar aquele, precisa de um bom de lábia para levar aquela outra.

105 Interv: E o que exatamente, no $\mathrm{CD}$, te fez ver isso?

106 Moisés: A escuta me fez, porque quando a Ana fala [nos comentários dela] que ela gosta mais de agir com os meninos mais molinhos, então ela tem lábia, ela tem domínio de mãe, de avó, ela é meiga, carinhosa para lidar com esses meninos, entende? E é o meu caso, porque eu já não tenho essa lábia, essa força para lidar com menino de argumento, menino valente, que fala mais, sabe mais etc. e tal, entende? [Silêncio].

No processo, Moisés interrogava seu estilo de cuidar e revivia antigos debates interiores sobre a atividade, normalmente endereçados à colega Ana, experiente na função (com 24 anos de casa), mãe e cuja maneira de agir o coloca em constantes discordâncias, implícita e explicitamente, e também aos colegas. Muitos a chamam de "mãezona", porque ela chega a descumprir prescrições médicas, nutricionais, por exemplo, alegando ter pena do interno por causa da restrição. Neste caso, ela age dando-lhe dois ou mais pratos de feijoada, ignorando seu tratamento. Atitudes assim afetam seus colegas de trabalho. Quanto a Moisés, seus dilemas traziam uma pergunta sobre o cuidado e a maternidade e outra sobre o reconhecimento de seu trabalho: "Será que ninguém reconheceu?". Por meio das IS ele pôde deslocar alguns sentidos e vivenciar novas experiências, permitindo-lhe agir/entender, com mais propriedade, em relação a seu próprio estilo e ao estilo da colega (Ana) presente na mesma atividade e, que antes, muito lhe incomodava, além de responder à sua própria demanda de reconhecimento. Esta encontra um caminho psicologicamente mais interessante: o da ação, que lhe permitiu compreender, de outra forma, a atividade e suas demandas perante o objeto, sua própria atividade necessariamente articulada a dos colegas e como tal dinâmica faz parte da sua maneira de fazê-la. Diante o real da atividade, Moisés entende sua própria atividade como algo que o ultrapassa, indo além dele e do que ele faz, sendo pertencente a esse algo maior, coletivo e interdependente, reconhecendo-se nesse lugar (o que é evidente também nos enunciados 104 e 106). As diferenças transformam-se em recurso para agir melhor. Na base dessa transformação, há um deslocamento do pensamento envolvendo as três instâncias do ofício: partindo do pessoal - "meu trabalho é continuação do trabalho do outro" -, ele introduz o nível interpessoal - "as diferenças e divergências de cada cuidador é que fazem a missão fluir" 
- para chegar ao transpessoal - "isso faz que várias cabeças pensem mais, chegando a uma só conclusão para atender ao outro com a maior precisão possível”. Estaria Moisés, por meio desse movimento, atualizando a função psíquica do ofício na sua atividade? (Clot, 2010).

Além disso, ele entende que a atividade de cuidar não está orientada por princípios gerais como os da emoção, da igualdade do agir ou mesmo da maternidade, tão presentes antes em seu discurso (e de seus colegas). Tal mudança de posição de Moisés, também em relação ao agir da colega, é evidente no enunciado 106, no qual ele situa seu fazer a partir do de Ana: desloca seu pensamento da instância interpessoal do ofício - "ela tem lábia, tem domínio de mãe, de avó, ela é meiga, carinhosa para lidar com esses meninos, entende?" - para a pessoal, realizando um movimento de singularização interessante - "eu já não tenho essa lábia pra lidar com menino de argumento, menino valente, que fala mais, sabe mais etc. e tal, entende?" - interrogando seu próprio estilo profissional (Clot, 2010; Clot \& Faita, 2000), trazendo-o para a experiência atual.

Constata-se que a problemática posta anteriormente, relativa à qualidade do trabalho praticado, estava sendo trabalhada por eles: o fazer do colega afeta a realização da atividade do sujeito e de sua relação com o real da atividade: todas as possibilidades que sua atividade comporta e, por motivos diversos, não são realizadas. Assim, o fazer do colega coloca em xeque a maneira de agir do sujeito, interrogando-a em sua relação com a eficiência e com o sentido (Clot, 2010). O que, aparentemente, se manifesta como uma preocupação de ordem interpessoal - manter uma boa relação com o colega - revela ser da ordem do agir profissional, como um caminho necessário para a ação e sua qualidade. A demanda dos cuidadores alude a um sentido clínico, porque se endereça a um fazer de qualidade, reconhecendo, no percurso deste fazer, seus dilemas. Ela nos sinaliza que é preciso cuidar do ofício para melhor exercer o ofício (ou o trabalho) de cuidar.

Retomamos Vygotski, entendendo as palavras como atividade em movimento, contrariamente à ideia clássica de que elas são o veículo de expressão do vivido, restringindo-o a uma ação passada. Com a ajuda de Clot (2001, p. 133), entendemos melhor os efeitos, para Moisés, dos diálogos realizados:

Em se transformando em linguagem, as atividades se reorganizam e se modificam. A linguagem, graças a qual o sujeito se endereça ao seu interlocutor, na troca que constitui o comentário sobre sua atividade, faz retornar em direção ao objeto analisado os efeitos dessa troca. As atividades, desde então, não se exprimem nas palavras que lhes serviriam somente de veículos amorfos para falar disso. Graças à linguagem endereçada ao outro, o sujeito realiza, no sentido forte do termo, suas atividades.

Outro dado é que, usando as três formas de linguagem - a oral, o debate interior e a escrita (Scheller, 2001b) -, Moisés reatualiza, de maneira singular, significações sociais e históricas comuns ao ofício de cuidar: a do cuidado como dimensão relacional, emocional e afetiva (Guimarães, Hirata \& Sugita, 2010; Masson, Brito \& Souza, 2008; Sorj, Fontes 2010), a do cuidado como prestação de serviço, elucidando a perspectiva de uma compensação das desigualdades (Tronto, 2009), a dimensão doméstica do cuidado e sua intrínseca relação com o gênero (Guimarães, Hirata \& Sugita, 2010; Tronto, 2009) e, por fim, a de uma ética do cuidado (Molinier, Laugier \& Paperman, 2009; Tronto, 2009), na medida em que, buscando definir seu trabalho, consegue romper com algumas dimensões morais e com as invisibilidades que as acompanham (como a de gênero, por exemplo), sem desconsiderar os valores tradicionalmente ligados às atividades femininas, vistos como presentes no ofício, dependendo das especificidades da situação que os exige.

Ainda que desenvolvimentos isolados tenham ocorrido, como é o caso de Moisés, em vários momentos do processo da intervenção, a pesquisa também revela que os cuidadores envolvidos agiam desprovidos da função psicológica e técnica própria ao gênero profissional. Seguindo a orientação de "buscar o ofício no indivíduo e não o indivíduo no ofício" (Clot, 2010, p. 285), dois 
argumentos dialógicos interligados nos levaram até esse ponto: as explicações e caminhos que os cuidadores construíam acerca de suas dificuldades na atividade apresentavam um teor pessoal e individualizante e, como saída para seus impasses, recorriam com frequência à hierarquia, por motivos variados, conforme conveniências e circunstâncias. Tais recursos singulares falseiam, em cada situação, um poder de agir ilusório, tanto deles quanto das supervisoras, porque é precário e pontual, não alimentando as instâncias sociais do ofício (a da tarefa e a transpessoal). $O$ apelo à hierarquia é uma alternativa na busca pela eficiência e para se proteger do risco de uma ação desregrada, prestes à transgressão. Porém, a qualidade da atividade continua em risco. Diferentes situações empíricas discutidas evidenciam a precariedade das ações, oriunda de uma interpretação individualizante do trabalho e, portanto, geradora de culpa, quando o que se discutia, na verdade, era relativo à dimensão coletiva do trabalho. Na passagem do plantão da noite para o do dia, por exemplo, duas situações foram alvo de discordâncias entre eles: ao assumirem o trabalho às sete horas da manhã, ouviam dos colegas do turno noturno que "tudo estava certo" e ao se aproximarem dos internos para levantá-los, encontravam-os sujos, sendo que a regra é deixá-los limpos para o plantão diurno. Além disso, tinham de enfrentar os atrasos frequentes de um colega (que não fazia parte da intervenção) pela manhã, comprometendo todo o restante da rotina matinal, além de exigir maior esforço físico das duas colegas na ação de limpar os internos, trocar suas roupas etc. Lembrando que o cuidador do sexo masculino é "valorizado" nos grupos de internos com maior deficiência motora ou com alto nível de agressividade. Ambas as dificuldades requeriam um debate sobre os valores convergentes e divergentes da respectiva ação situada, buscando uma redefinição de outros caminhos para a ação por parte deles. Entretanto, tanto a ausência do colega como a passagem dos internos sujos eram tomadas como um problema de consciência dos profissionais, não cabendo às colegas o direito de discutir a respeito, mesmo diante de nossas intervenções, que apontavam para algo maior. Segue um breve trecho do diálogo durante os comentários com o grupo II:

78 Karen: Giselle, eu escutei o CD umas três vezes. Eu não gostei do jeito que você fazia a resposta, aí você falava assim: eu, Karen, aí eu respondia com a voz... mudou totalmente... eu me senti assim num... parece que estava assim num...

79 Flavia: Interrogatório?

80 Karen: Interrogatório, sabe. Eu falei coisas que não tinha necessidade de falar, não.

81 Interv: O quê, exatamente?

82 Karen: Sobre o compromisso, cada um tem que ter seu compromisso, eu falei do compromisso de horário e eu acho que sobre o compromisso de horário eu não devia ter falado.

83 Interv: O quê, exatamente?

84 Karen: Sobre o compromisso de meus colegas chegarem no horário certo, chegava sempre atrasado, no horário do café da manhã. Eu falei do compromisso do pessoal da noite, em deixar os meninos molhados ou de cocô. Eu não deveria ter falado isso, porque cada um sabe do seu compromisso. Eu tenho meu compromisso, você tem, ela tem. Eu acho que isso aí não cabia eu falar do compromisso das pessoas, porque elas têm compromisso diretamente com os meninos, e não comigo, entendeu? E aquilo ali me incomodou um pouco, não deveria ter falado, não.

Outra evidência de que os cuidadores estejam sozinhos na atividade pode ser vista na forma como apropriam-se da regra institucional "aqui todos cuidam de todos" e que fora criada para que todos os cuidadores se encarreguem, em tempo integral, de todos os internos, mesmo não estando diretamente sob sua responsabilidade, minimizando-se assim as situações de risco destes. Essa regra se apresenta aos cuidadores como um conflito. No intuito de cumpri-la, a cuidadora Joana (com 6 meses de casa), que é particular do interno César, ao ver que um interno "fugira" do grupo 
dele e achava-se próximo a ela e ao César, vê-se obrigada a acolhê-lo de alguma forma. Como tal situação é frequente, ela resolve acolhê-lo, indignada com a displicência de sua colega, e deixa César sob riscos e olhares de outros colegas para ir pegar o interno que fugira. Diante do dilema de cumprir ou não a regra, Joana cumpre, mas resguarda-se dos riscos, passando na sala da supervisão, onde mostra que, por estar com o interno de outro grupo, cumprindo a regra, César corria riscos enquanto delatava colegas. Tais estratégias individuais e comuns ocorrem pela impossibilidade desses grupos de cuidadores discutirem entre si as regras, seus impasses, suas necessidades e as variabilidades do trabalho no cotidiano. Explicam-se, assim, os comportamentos de delação direta e indireta entre os profissionais, os privilégios e favoritismos arbitrários, intensificando os conflitos interpessoais, a fragilidade dos acordos implícitos entre eles e as ações de transgressão da tarefa, aumentando os riscos dos internos para fazer a atividade. Resgatando a problemática posta inicialmente pelos cuidadores sobre como lidar com as diferenças, percebe-se que ela já aludia a um coletivo de trabalho esvaziado em sua função de referência técnica e psicológica à atividade ali desenvolvida, individual e coletivamente. É bom lembrar que um dos efeitos da ausência de um gênero ativo no meio profissional é exatamente a perspectiva de tomar a ação como uma transgressão, no nível individual (Clot, 2010; Caroly \& Clot, 2004), cujos riscos cada um assume sozinho. A transgressão confirma a falência do gênero, camuflada através da prescrição formal (Clot, 2010). Portanto, é preciso cuidar do ofício para melhor cuidar, assim, os desenvolvimentos isolados poderão promover desenvolvimentos da atividade no âmbito do coletivo e da organização.

\section{Considerações finais}

Nossa primeira experiência em CA nos deixa um saldo altamente positivo em termos do que foi realizado pelos cuidadores e por nós, e igualmente do que não foi realizado e nos incita à continuidade dos trabalhos, apresentando-se como o real das nossas atividades de gerar intervenções e de pesquisadores. Do ponto de vista das limitações encontradas, dois fatores interligados são considerados: o tempo demasiadamente curto para desenvolver os processos de aprendizado, na França, e de aplicação, no Brasil, sendo insuficiente para a vivência necessária da metodologia e do método com a equipe da CA, no Conservatoire des arts et métiers, e com os profissionais, no Brasil, e a articulação da empiria aos domínios teórico e metodológico por meio de uma abordagem de análise da intervenção e dos desenvolvimentos ainda pouco clara para nós, brasileiros. Como efeito, a pesquisa nos revela a necessidade de desenvolvermos dois aspectos: a) de explorarmos de maneira mais aprofundada o princípio da controvérsia nos diálogos, dando foco às especificidades da atividade discutida e orientando os profissionais ao exercício sistemático de uma coanálise sobre a atividade situada - no horizonte, seus desdobramentos poderiam facilitar novos desenvolvimentos por parte dos profissionais envolvidos e a localizá-los, além de acenar para uma futura etapa que envolvesse as instâncias hierárquicas relacionadas, como prevê a abordagem -; b) avançarmos nos estudos sobre os caminhos para uma análise dialógica, durante e após a intervenção. Ambos são desafios muito complexos.

Seguindo estas pistas e buscando dar continuidade aos trabalhos, iniciamos, no ano de 2014, outra intervenção com a mesma organização e seus cuidadores, nos termos formais de uma pesquisa aprovada e financiada pela Pontifícia Universidade Católica de Minas Gerais. Um de seus focos era aprofundar questões discutidas por eles e seus efeitos em suas atividades ordinárias, conduzindo-os a uma melhor apropriação sobre as causas e impactos da ausência do gênero profissional no exercício cotidiano da atividade e conduzindo-nos a encaminhamentos de muitas das questões sobre uma clínica da atividade possível no Brasil. 


\section{Referências}

Bakhtin, M. (1997). Estética da criação verbal (M. E. G. G. Pereira, trad.). São Paulo, SP: Martins Fontes, 1997.

Canguilhem, G. (2005). Escritos sobre a medicina. Rio de Janeiro, RJ: Forense Universitária.

Canguilhem, G. (2009). O normal e o patológico. Rio de Janeiro, RJ: Forense Universitária.

Caroly, S., \& Clot, Y. (2004). Du travail collectif au collectif de travail. Des conditions de développement des stratégies d'expérience. Comparaison de deux bureaux de Poste. Formation et Emploi, 88, 43-55. Recuperado de http:// formationemploi.revues.org/

Clot, Y. (1998). Le travail sans l'homme? Pour une psychologie des milieux de travail et de vie. Paris: La Découverte.

Clot, Y. (2001). Méthodologie en clinique de l'activité. L'exemple du sosie. In: M. S. Delefosse \& G. Rouan (Orgs.), Les méthodes qualitatives en psychologie (pp. 133-147). Paris: Dunod.

Clot, Y. (2003). Vygotski, la conscience comme liaison. In: L. Vygotski (2003) Conscience, inconscient, émotions. Préface. (G. Fernandez, trad.). Paris: La Dispute. (Original publicado em 1925).

Clot, Y. (2006). A função psicológica do trabalho. (A. Sobral, trad.). Petrópolis, RJ: Vozes.

Clot, Y. (2008). La recherche fondamentale de terrain: une troisième voie. Éducation Permanente, 177, 2004-2008. Recuperado de http://www.education-permanente.fr

Clot, Y. (2010). Trabalho e poder de agir. (G. J. Freitas e M. M. Z. Vianna, trad.). Belo Horizonte, MG: Fabrefactum.

Clot, Y. (2011). Pourquoi l'activité dans la clinique du travail? In Y. Clot \& D. Lhuilier. Agir en clinique du travail. Toulouse: Érès.

Clot, Y.; Faita, D. (2000) Genres et styles en analyse du travail: concepts et méthodes. Travailler, 4, 7-43. Recuperado de http://www.cairn.info/revue-travailler.htm

Clot, Y., \& Fernandez, G. (2005). Analyse psychologique du mouvement: apport à la comprehension des TMS. Activités, 2(2), 69-78. Recuperado de http://www.activites.org/v2n2/fernandez.pdf.

Daumézon, G. (1948). Lapplication pratique des thèses nouvelles en assistance psychiatrique. Information psychiatrique, 9, 239-246.

Guimarães, N. A., Hirata, H. S., \& Sugita, K. (2010). “Care” et "Care work”. Le travail du "care” au Brésil, en France, au Japon (version préliminaire). Coletânea Colóquio Internacional "O que é o care? Emoções, Divisão do Trabalho, Migrações”. Programa de Pós-gradução em Sociologia da USP (no prelo). Recuperado de http://www.fflch.usp. br/ds/pos-graduacao/2010_coloquio_care.html

Kostulski, K. (2011). Quelles connaissances pour l'action en clinique du travail? Une contribuition à la question des rapports entre les actions de transformation et la production de connaissances en clinique du travail. In Y. Clot \& D. Lhuilier. Agir en clinique du travail. Toulouse: Érès.

Le Guillant, L. (1985). Quelle psychiatrie pour notre temps? Toulouse: Érès.

Le Guillant, L. (2006). Escritos de Louis Le Guillant. Petrópolis, RJ: Vozes.

Léontiev, A. N. (1976). Le développement du psychisme. Paris: Sociales

Leplat, J. (1997). Regards sur l'activité en situation de travail. Paris: PUF.

Lhuilier, D. (2007). Cliniques du travail. Ramonvile Saint-Agne: Érès.

Lima, M. E. A. (2011). Abordagens clínicas e saúde mental no trabalho. In P. Bendassoli \& L. Sobol. Clínicas do Trabalho. Novas perspectivas para compreensão do trabalho na atualidade. São Paulo, SP: Atlas.

Litim, M. (2006). Les histoires de travail: un instrument du développement du métier et de l'activité professionnelle (Tese de Doutorado). Paris: CNAM.

Masson, L. P., Brito, J., \& Souza, R. N. P. (2008). O trabalho e a saúde de cuidadores de adolescentes com deficiência: uma aproximação a partir do ponto de vista da atividade. Saúde e Sociedade, 17(4), 68-80. Recuperado de www. scielo.br/scielo.php?pid=S0104-12902008000400008

Miossec, Y., \& Clot, Y. (2011). Le métier comme instrument de protection contre les risques psychosociaux au travail: le cas d'ingénieurs managers de proximité. Le Travail Humain, LXXIV(4), 341-364. Recuperado de http://www. cairn.info/revue-le-travail-humain.htm 
Molinier, P., Laugier, S., \& Paperman, P. (Orgs.) (2009). Qu'est-ce que le care? Souci des autres, sensibilité, responsabilité. Paris: Payot \& Rivages.

Oddone, I., Re, A., \& Briante, G. (1981). Redécouvrir l'expérience ouvrière. Vers une autre psychologie du travail? Paris: Sociales.

Osty, F. (2003). Le désir du métier: engagement, identitté et reconnaissance au travail. Rennes: PUR.

Scheller, L. (2001a). Lélaboration de l'expérience du travail. La méthode des instructions au sosie dans le cadre d'une formation universitaire. Education Permanente, 1(146), 160-173. Recuperado de http://www.educationpermanente.fr/

Scheller, L. (2001b). Lexpérience du travail dans le cadre dialogique. Travailler, 2(6), 71-88. Recuperado de http://www. cairn.info/revue-travailler.htm

Scheller, L. (2003). Élaborer l'expérience du travail: activité dialogique et référentielle dnas la méthode des instructions au sosie (Tese de Doutorado). Paris: CNAM.

Scheller, L. (2007). Clinique de l'activité et élaboration de conflits dans le travail: une methode d'action. In Perspectives en education et formation (pp. 89-109).

Simonet, P. (2009). L'examen méthodique d'un geste de métier pour une prevention durable de TMS: une intervention en Clinique de l'activité. Pistes, 11 (2), 2-12. Recuperado de http://www.pistes.uqam.ca/v11n2/

Simonet, P. (2011). L'hypo-socialisation du mouvement. Prévention durable des troubles musculo-squelettiques chez des fossoyeurs municipaux (Tese de Doutorado). Paris: CNAM.

Sorj, B., \& Fontes, A. (2010). O care como regime estratificado: implicações de gênero e classe social no Brasil. Coletânea Colóquio Internacional "O que é o care? Emoções, Divisão do Trabalho, Migrações”. Programa de Pós-gradução em Sociologia da USP. (no prelo).

Tomàs, J-L. (2005). Deux voies de développement de l'activité de pensée em autoconfrontation croisée: le cas de deux sportifs de haut niveau em haltérophilie (Tede de Doutorado). Paris: CNAM.

Tosquelles, F. (2009). Le travail thérapeutique en psychiatrie. Toulouse: Érès.

Tronto, J. (2009). Un monde vulnérable: pour une politique du care. Paris: La Découverte.

Vygotski, L. (1978). Mind in Society: the development of higher psychological processes. Cambridge: Harvard University Press.

Vygotski, L. (1994). Défectologie et déficience mentale. Textes publiés par K. Barisnikov et G. Petitpierre. Lausanne: Delachaux \& Niestlé.

Vygotski, L. (1997). Pensée et Langage. (3a ed., F. Sève, trad.). Paris: La Dispute. (Original publicado em 1934)

Vygotski, L. (1998). Théorie des émotions: étude historique-psychologique. Paris: L'Harmattan.

Vygotski, L. (2003). Conscience, inconscient, emotions. (F. Sève \& G. Fernandez, trad.). Paris: La Dispute. (Original publicado em 1925).

Vygotski, L. (2004). Psychologie concrète de l'homme. In M. Brossard. Vygotski. lectures et perspectives de recherche em éducation. Villeneuve d'Ascq: Septentrion.

Wallon, H. (2002). Les origines du caractère chez l' enfant. Paris: PUF. (Original publicado em 1949)

Wisner, A. (1995). Réflexions sur l'ergonomie. Toulouse: Octarès.

\section{Endereço para correspondência grbrandao40@gmail.com}

Recebido em: 17/03/2014

Revisado em: 08/03/2015

Aprovado em: 23/03/2015 